УдК 536.242

О.Ю. Пилипенко ${ }^{1}$, А.В. Форсюк ${ }^{1}$, Я.І. Засядько ${ }^{1}$ В.С. Глушков ${ }^{2}$

${ }^{1}$ Національний університет харчових технологій, вул. Володимирська, 68, м. Київ, 01601

2 Філія "Гаврилівський птахівничий комплекс" ТОВ "Комплекс Агромарс",

с. Гаврилівка, Вишгородський р-н, Київська обл., 07350

\title{
ВИЗНАЧЕННЯ КОЕФІЦІЄНТУ ТЕПЛОВІДДАЧІ ПРИ КИПІННІ ХОЛОДИЛЬНИХ АГЕНТІВ В АКУМУЛЯТОРАХ ХОЛОДУ
}

\begin{abstract}
Використання розрахункових співвідношень які б адекватно описували теплообмін між теплообмінною поверхнею та холодильним агентом $\epsilon$ вкрай необхідним для точного конструктивного розрахунку чи підбору теплообмінного обладнання холодильних установок, в тому числі, акумуляторів холоду. 3 врахуванням існуючих обмежень до обраних з огляду літературних джерел співвідношень, проведено математичне моделювання прочесу теплообміну під час кипіння холодильних агентів та виконано графічне порівняння результатів розрахунку за моделлю та обраними розрахунковими співвідношеннями. Проведений аналіз дозволив обрати залежність яка, може бути використана в інженерних розрахунках акумуляторів холоду з накопиченням льоду на поверхні теплообміну.

Ключові слова: коефічієнт тепловіддачі - теплопередача - теплообмін - кипіння масовий потік - тепловий потік - льодоакумулятор - акумулятор холоду - холодильний агент
\end{abstract}

\author{
А.Ю. Пилипенко ${ }^{1}$, А.В. Форсюк ${ }^{1}$ Я.И. Засядько ${ }^{1}$, В.С. Глуиков ${ }^{2}$ \\ ${ }^{1}$ Национальный университет пищевых технологий, ул. Владимирская, 68, г. Киев, 01601 \\ ${ }^{2}$ Филиал "Гавриловский птицеводческий комплекс" ООО "Комплекс Агромарс", \\ с. Гавриловка, Вышгородский р-н, Киевская обл., 07350
}

\section{ОПРЕДЕЛЕНИЕ КОЭФФИЦИЕНТА ТЕПЛООТДАЧИ ПРИ КИПЕНИИ ХОЛОДИЛЬНЫХ АГЕНТОВ В АККУМУЛЯТОРАХ ХОЛОДА}

Использование расчетных соотночений, которые адекватно описывали бы теплообмен между поверхностью и холодильным агентом, является крайне необходимым для точного конструктивного расчета или подбора теплообменного оборудования холодильных установок. Литературный обзор уравнений для определения коэффициента теплоотдачи при кипении вещееств в каналах различной формы и условий проведения прочесса позволил провести математическое моделирование теплообмена при кипении холодильных агентов с учетом существующих ограничений к избранным соотношениям. Выполнено графическое сравнение результатов. Проведенный анализ позволил выбрать зависимость, которая может быть использована в инженерных расчетах аккумуляторов холода.

Ключевые слова: коэффициент теплоотдачи - теплопередача - теплообмен - кипение массовый поток - тепловой поток - лёдоаккумулятор - аккумулятор холода холодильный агент

DOI: $10.15673 / 0453-8307.1 / 2015.31107$

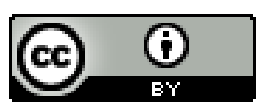

\section{I. ВСТУП}

3 метою зменшення встановленої потужності холодильного обладнання на підприємствах, де має місце значне коливання потреби в штучному охолодженні, наприклад молокозаводи, та потужних системах кондиціювання повітря
This work is licensed under the Creative Commons Attribution International License (CC BY). http://creativecommons.org/licenses/by/4.0/ 
Однак процес розрахунку та підбору льодоакумуляторів наштовхується на ряд складнощів. В основному вони пов'язані 3 відсутністю методики розрахунку, яка б враховувала динаміку наморожування льоду за постійного тиску кипіння та його подальшого плавлення.

Ряд досліджених робіт направлені на вирішення поставленої проблеми, однак виникають i суміжні питання. Так в запропонованому рівнянні розрахунку динаміки льодоутворення на вертикальній трубі [1] особливої уваги потребує визначення коефіцієнту тепловіддачі при кипінні холодильного агенту $\alpha_{0}$. Оскільки, як на початку, так i в процесі льодоутворення, можуть проявлятися різні режими кипіння, які заздалегідь прогнозувати проблематично. При цьому, як показує аналіз літературних джерел, одночасно можуть проявлятися різні режими теплообміну (рис. $1[2,3,4])$.
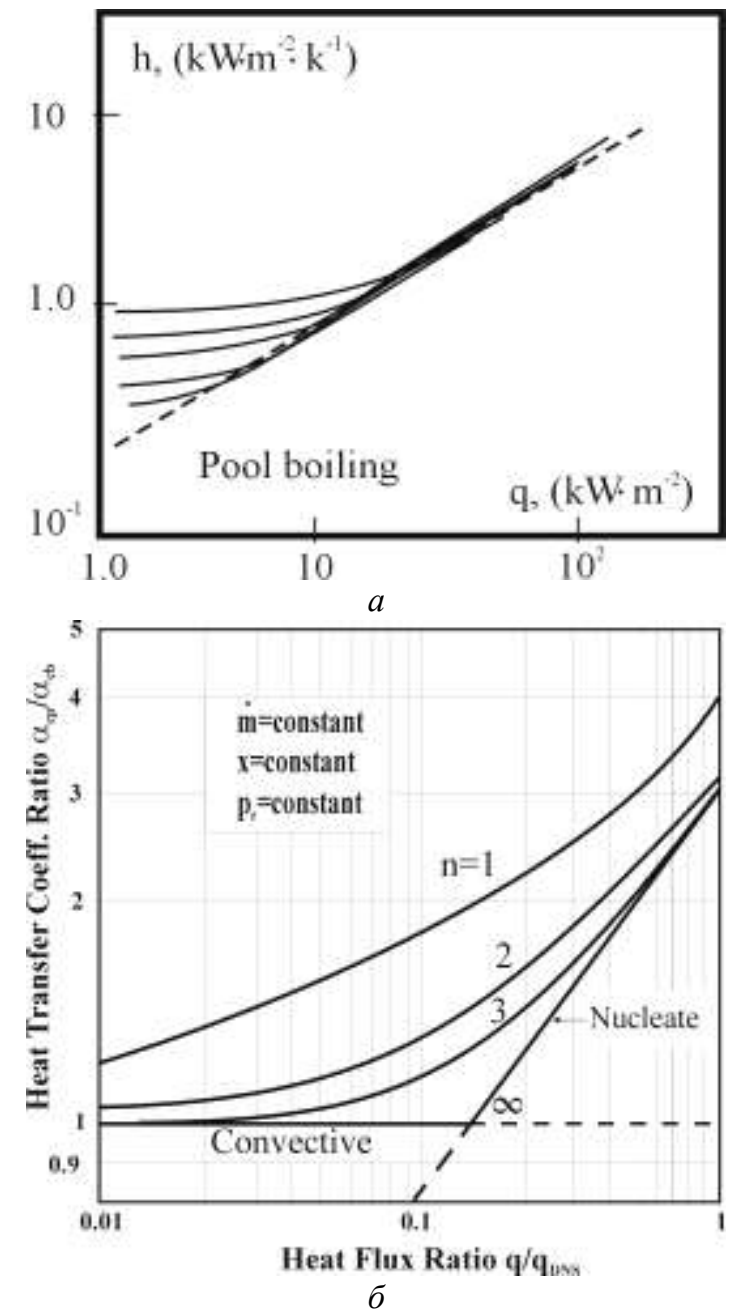

Рисунок 1 - Зал ежності коефіиієнту тепловіддачі холодильного агенту від густини теплового потоку:

$$
a-3 a[2] ; 6-3 a[3]
$$

Метою даної роботи $є$ пошук співвідношень які 6 адекватно описували процес теплообміну між внутрішньою поверхнею роздільної стінки та холодильним агентом.

\section{II. АНАЛІЗ ІСНУЮЧИХ СПІВВДНОШЕНЬ 3 РОЗРАХУНКУ КОЕФІЦІЕНТУ ТЕПЛОВІДДАЧІ ПРИ КИПІННІ}

Як відомо кипіння - це процес переходу речовини із рідкого стану у газоподібний, що характеризується виникненням нових вільних поверхностей поділу рідкої та парової фаз у середині рідини, нагрітої вище температури насичення [5].

Під час літературного пошуку основна увага приділялася нерозвиненому (НБК) та розвиненому бульбашковому кипінню (РБК) у великому об'ємі (ВО), каналах (К) та трубах: вертикальних (ВТ) i горизонтальних (ГТ). Нерозвинуте бульбашкове кипіння за певних умов може переходити у конвективний теплообмін (КТ) між внутрішньою поверхнею труби та холодильним агентом, про що свідчить рисунок 1 [2, 3].

Обрані для подальшого аналізу співвідношення, зведені до табл. 1, є переважно функцією теплового потоку $\alpha_{0}=f(q)$. При цьому кожному рівнянню вигляду $\alpha_{0}=f(q)$ відповідає співвідношення $\alpha_{0}=f(\Delta T)$, де $\Delta T-$ різниця температур внутрішньої поверхні труби та температури насичення. Співвідношення для плівкового кипіння не обиралися, оскільки у випарниках холодильної техніки тепловий потік для виникнення такого роду кипіння є практично недосяжним.

Побіжний огляд обраних залежностей показує, що більшість 3 них описує процес розвинутого бульбашкового кипіння у великому об'ємі (ВО-РБК) та обмежена кількість - кипіння в трубах та нерозвинуте бульбашкове кипіння у великому об'ємі (ВО-НБК).

Більшість авторів пропонують проводити розрахунки використовуючи числа подібності, що ускладнює ці розрахунки необхідністю визначення параметрів, які до них входять. Частину рівнянь автори представляють у розмірному вигляді, основою для яких є загальне рівняння (4) наведене у табл. 1 .

Розрахункова залежність для визначення коефіцієнта тепловіддачі при кипінні, у більшості випадків, може бути представлена загальним виразом $\alpha_{0}=C \cdot q^{n}$, коефіцієнти якого у різних авторів відмінні для однакових умов проведення процесу та виду речовини.

Для аналізу, також, обрано співвідношення для води, розрахунки кипіння за якими, добре корелюється 3 дослідними даними та співвідношення рекомендовані авторами для широкого кола речовин (в табл. 1 не мають вказівки на речовину).

Використавши програму MathCAD, за обраними для аналізу розрахунковими залежностями (табл. 1), проведено варіативні розрахунки для температури кипіння $t_{0}=-10{ }^{\circ} \mathrm{C}$ в діапазоні теплових потоків $-q=0 \div 30$ кВт/м ${ }^{2} 3$ подальшим графічним порівнянням одержаних результатів (рис. 2). Під час проведення 
розрахунків, були враховані обмеження, накладені на аналізовані рівняння. Теплофізичні властивості хладонів визначали за довідниками [12] та [13].

Дані розрахунків представлені на рисунку 2 у вигляді кривих мають значну розбіжність. Так результати розрахунку за рівняннями для режиму розвинутого бульбашкового кипіння, за теплового потоку 30 кВт/м², відрізняються в 19,5 раз. Частина рівнянь $(4,5,6,7,8)$, рекомендованих авторами для розвинутого бульбашкового кипіння, демонструють тепловіддачу меншу, ніж для режиму вільної конвекції рідини запропонованої автором залежності (2). Формули рекомендовані для широкого кола речовин $(7,8,11)$, після розрахунку коефіцієнту тепловіддачі при кипіння фреону R12 за чисельними значеннями співпадають 3 рівняннями, одержаними безпосередньо для R12 (5).

Таблиця 1 - Розрахункові залежності для визначення коефіцієнту тепловіддачі при кипінні

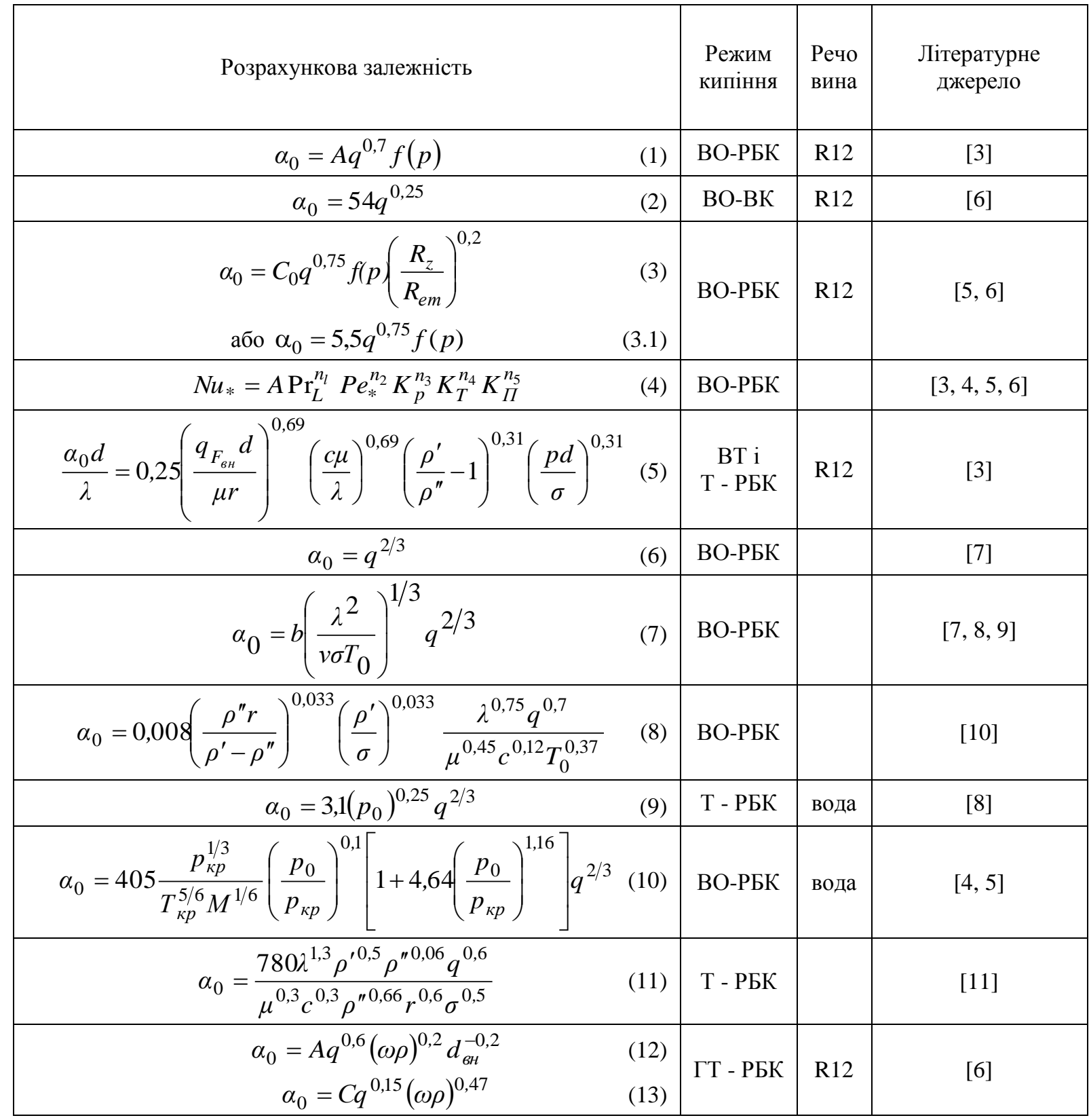

Рівняння (9) та (10), що використовуються для розрахунку тепловіддачі при кипінні води, у випадку для R12 мають абсолютно однакові значення. Криві побудовані за цими рівняннями окреслюють верхню межу можливих значень коефіцієнту тепловіддачі при кипінні хладонів.

Рівняння загального вигляду $\alpha_{0}=C \cdot q^{n}$, одержані для кипіння хладонів, демонструють результати розрахунків, за характером, наближені до кривих 9 та 10 (рис. 2).

Розбіжність значень, одержаних за рівняннями (1) та (3), можна пояснити впливом шорсткості дослідної труби, що підтверджується розбіжністю значень рівнянь (3) та (3.1), порахованого 3 та без врахування поправки на шорсткість поверхні теплообміну $\left(R_{z} / R_{e m}\right)^{0,2}$. 


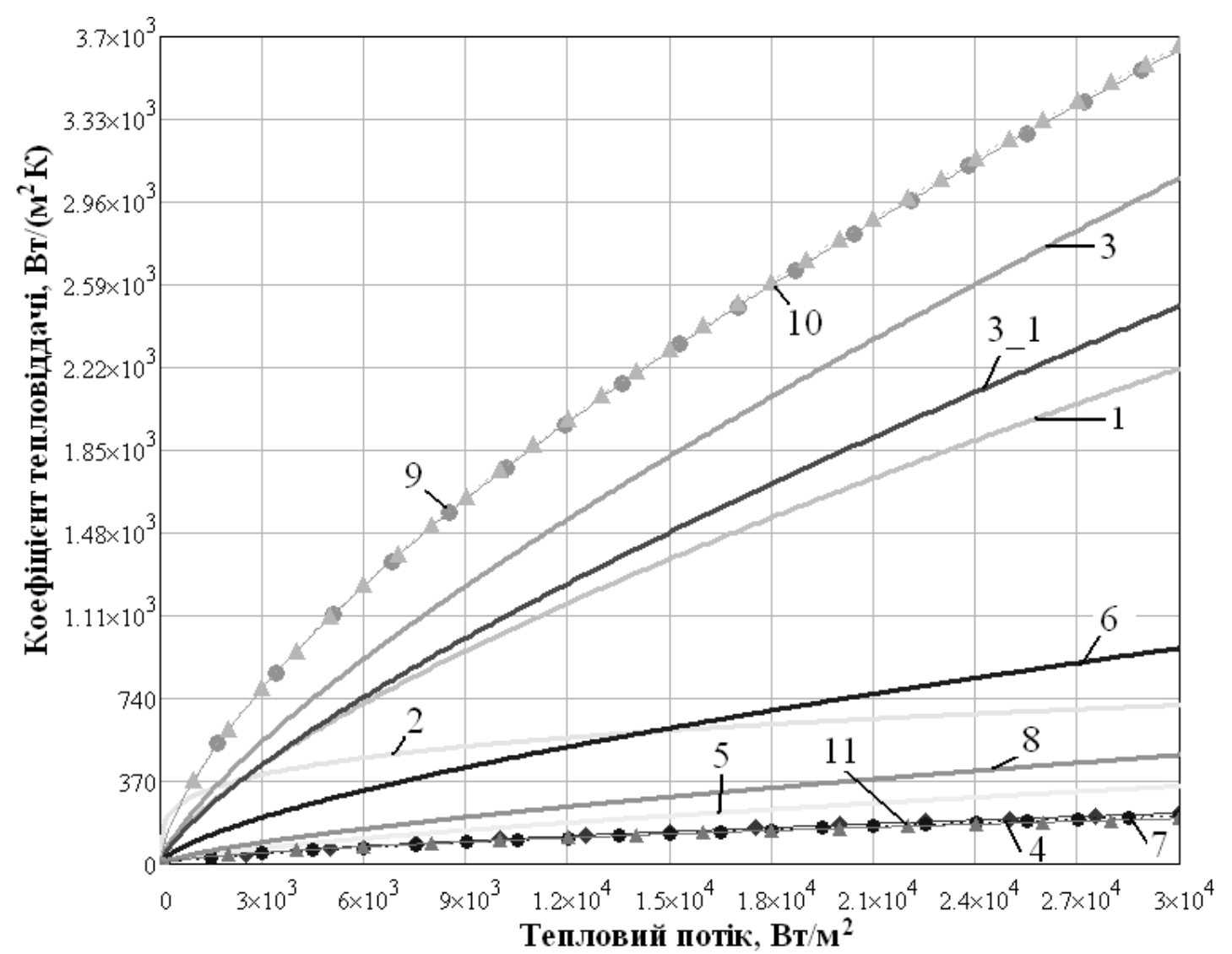

Рисунок 2 - Зміна коефіцієнту тепловіддачі при кипінні $\alpha_{0}$ від теплового потоку q: нумерація кривих відповідає нумерації рівнянь в табл. 1; криві 3 та 3 _ розраховані за рівнянням (3) з та без поправки на шорсткість труби відповідно

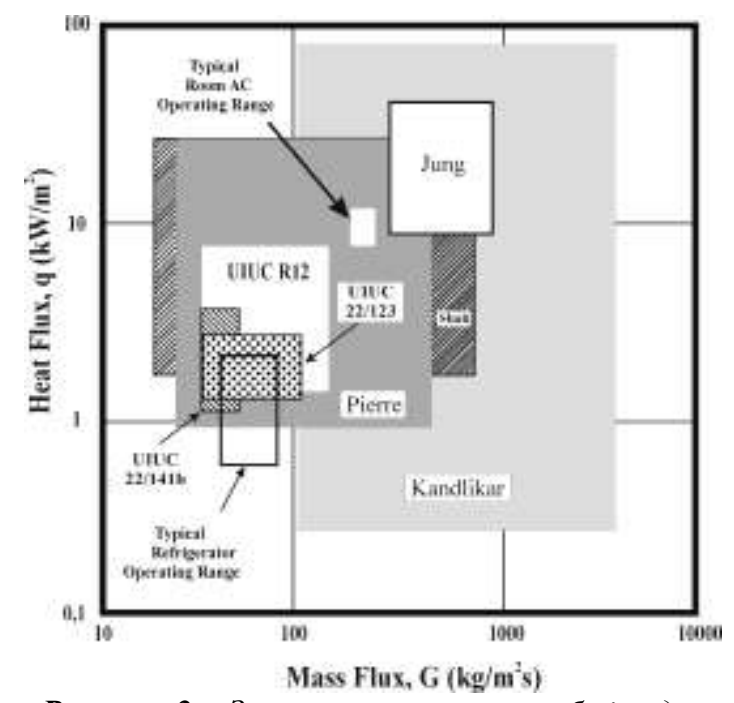

Рисунок 3 - Зони вивченого теплообміну для систем промислового холодопостачання та кондииіювання повітря [14]

Для наведених в табл. 1 формул, немає обмежень за тепловим потоком. Лише Данілова Г.Н. [6] наводить різні значення коефіцієнтів для рівняння вигляду $\alpha_{0}=C \cdot q^{n}$ залежно від теплового потоку. Критерієм вибору цих коефіцієнтів є густина теплового потоку 1400 Вт/м². Нижче цього значення рекомендується приймати показник степені $n=0,25$. Таким чином, можна стверджувати, що при тепловому потоці меншому за 1400 Вт/м² відбувається зміна режиму теплообміну, що підтверджується іншими авторами (рис. $1[2,3])$.

Зважаючи на відсутність таких обмежень у інших авторів, можна зробити висновок, що режим кипіння за незначних теплових потоків недостатньо вивчене. Таке припущення підтверджується рисунком 3 [14], за яким видно, що для малих масових витрат холодильного агенту та незначних теплових потоків (до $1000 \mathrm{BT} / \mathrm{m}^{2}$ ) у теплообмінному обладнанні промислових холодильних установок процес кипіння майже не вивчався.

\section{III. ВИСНОВКИ}

Зважаючи на невизначеність механізму перенесення теплоти, а також на відсутність загальноприйнятого співвідношення для умов незначних теплових потоків та масових швидкостей, вважаємо за доцільне проводити розрахунки теплообміну в льодоакумуляторах за рівнянням (3).

Однак, внаслідок широкого використання альтернативних багатокомпонентних холодильних агентів, $є$ доцільним проводити дослідження 
теплообміну при кипіння за різних умов саме для цих речовин. Враховуючи значне зменшення теплового потоку в процесі льодоутворення на теплообмінній поверхні, особливу увагу необхідно приділяти теплообміну 3 малими масовим та тепловим потоками.

\section{ЛІТЕРАТУРА}

1. Пилипенко, О. Ю. Диференціальне рівняння визначення швидкості намороження льоду на вертикальній циліндричній поверхні [Текст] / О. Ю. Пилипенко, Я. І. Засядько // Обладнання та технології харчових виробництв : темат. зб. наук. пр. - 2012. - Вип. 29. - С. 160-168.

2. Shekriladze, I. G. Boiling Heat Transfer: Mechanisms, Models, Correlations and the Lines of Further Research [Текст] / I. G. Shekriladze // The Open Mechanical Engineering J. - 2008. - No. 2. P. 104-127.

3. John, R. T. Engineering Data Book III [Текст] /

R. T. John. - Wolverine tube, inc., 2010.

4. Fagerholm, N.-E. Boiling Heat Transfer in a Vertical Tube with Freon 114 [Текст] / N.-E. Fagerholm, A. R. Ghazanfari, K. Kivioja // Warmeund Stoffubertragung. - 1983. - Vol. 17. - P. 221232.

5. Василенко, С. М. Основи тепломасообміну [Текст] : підр. / С. М. Василенко, А. І. Українець, В. В. Олішевський ; за ред. І. С. Гулого. - К. : РВЦ НУХТ, 2004. - $250 \mathrm{c.}$

6. Теплообменные аппараты холодильных установок [Текст] / Г. Н. Данилова, С. Н. Богданов, О. П. Иванов и др. ; под общ. ред. Г. Н. Даниловой. - 2-е изд., перераб. и доп. - Л.: Машиностроение. Ленингр. отд-ние, 1986. - 303 с.
7. Михеев, М. А. Основы теплопередачи [Текст]/ М. А. Михеев, И. М. Михеева. - 2-е изд., стереотип. - М. : Энергия, 1977. - 344 с.

8. Цветков, Ф. Ф. Тепломассообмен [Текст] : учеб. пособие / Ф. Ф. Цветков, Б. А. Григорьев. 2-е изд., испр. и доп. - М. : Издательство МЭИ, 2005. $-550 \mathrm{c}$

9. Деев, В. И. Методика расчета теплообмена при кипении жидкости на поверхности нагрева [Текст] / В. И. Деев, Зар Ни Аунг, К. В. Куценко и др. // Ядерная физика и инжиниринг. - 2011. - Т. 2, № 5. - С. 387-394.

10. Толубинский, В. И. Теплообмен при кипении [Текст] / В. И. Толубинский. - К. : Наук. думка, 1980. $-316 \mathrm{c}$.

11. Виноградов, С.Н. Выбор и расчет теплообменников [Текст]: учеб. пособие / С. Н. Виноградов, К. В. Таранцев, О. С. Виноградов. - Пенза : Пензенский гос. ун-т, 2001. - 100 с.

12. Теплофизические свойства фреонов [Текст] : в 2 т. Т. 2 : Фреоны метанового ряда. Справочные данные / В. В. Алтунин, В. 3. Геллер, Е. А. Кременевская и др. ; под ред. С. Л. Ривкина. - М. : Изд-во стандартов, 1985. - 264 с.

13. Перельштейн, И. И. Термодинамические и теплофизические свойства рабочих веществ холодильных машин и тепловых насосов [Текст] / И. И. Перельштейн, Е. Б. Парушин. - М. : Легкая и пищевая пром-сть, 1984. - 232 с.

14. A Study of Evaporation Heat Transfer Coefficient Correlations at Low Heat and Mass Fluxes for Pure Refrigerants and Refrigerant Mixtures [Текст] : отчет o HИР / ACRC University of Illinois; principal investigator J. C. Chato. - ACRC TR-32. - Urbana, 1993. $-21 \mathrm{p}$.

O. Pylypenko ${ }^{1}$, A. Forsiuk ${ }^{1}$, Ya. Zasiadko ${ }^{1}$, V. Glushkov ${ }^{2}$

${ }^{1}$ National University of Food Technologies, 68 Volodymyrska str., Kyiv, 01601, Ukraine

${ }^{2}$ Complex Agromars Ltd., philia "Gavrilovsky poultry complex", village Havrylivka, Vyshgorodskiy area, Kyiv oblast, 07350, Ukraine

\section{DETERMINATION OF HEAT TRANSFER COEFFICIENTS OF BOILING REFRIGERANTS PERTINENT TO THE COLD ACCUMULATORS' CONDITIONS}

The use of correlations that would be capable to adequately account for the heat transfer between the surface and refrigerant are crucial for the accurate design calculations and proper heat transfer equipment sizing, including cold accumulators with ice generation on the heat transfer surface. A vast multitude of such correlations for the determination of overall heat transfer coefficient valid for different cross sections pipes and processes conditions are available now in the literature. The calculations of heat transfer pertinent to the conditions of cold accumulators, lead to the results drastically deviating from those obtained in the framework of the direct experimentation carried out at the Department of Power Engineering and Industrial Refrigeration of NUFT. In order to mark one or some of such correlations, that might have been used within the engineering calculations under condition of their proper correction, the critical comparative analysis of the literature sources has been carried out. The mathematical modeling of the heat transfer process in the condition of boiling refrigerant, with taking into account the valid limitations towards correlations, has been performed. The graphical comparison of the modeling results calculation with chosen correlations is performed. The results of the analysis allowed choosing the correlations, which could be recommended to be used within the engineering design calculations of cold accumulators with the ice accumulation on the heat transfer surface. The 
applications of such design correlations that adequately reflect the mechanism of heat transfer between the surface and refrigerant would be critical for the accurate design calculations of the transfer equipment of the refrigeration units, including cold accumulators with ice generation.

Key words: heat transfer coefficient - heat transfer - boiling - math flowrate - heat flax - ice accumulator - cold accumulator - refrigerant

\section{REFERENCES}

1. Pylypenko, O. Yu., Zasiadko, Ya. I. 2012. Development of a differential equation for determination of ice build-up time on the vertical cylindrical surface. Obladnannya ta tehnologii harchovih virobnitstv: temat. zb. nauk. pr., 29, 160 168.

2. Shekriladze, I. G. 2008. Boiling Heat Transfer: Mechanisms, Models, Correlations and the Lines of Further Research. The Open Mechanical Engineering J., No. 2, 104-127.

doi: 10.2174/1874155X00802010097

3. John, R. T. 2010. Engineering Data Book III. Wolverine tube, inc.

4. Fagerholm, N.E., Ghazanfari, A.R., Kivioja, K. 1983. Boiling Heat Transfer in a Vertical Tube with Freon 114. Warme- und Stoffubertragung, Vol. 17, 221-232.

5. Vasilenko, S M., Ukrayinets, A.I., Olishevskiy, V.V. 2004. Osnovi teplomasoobminu: pidr. Za red. I.S. Gulogo. - K.: RVTs NUHT, - 250 p. (in Ukranian)

6. Danilova, G. N., Bogdanov, S. N., Ivanov, O. P., i dr. 1986. Teploobmennyie apparaty holodilnyih ustanovok. 2-e izd., pererab. i dop. - L.: Mashinostroenie, -303 p. (in Russian)

7. Miheev, M.A., Miheeva, I.M. 1977. Osnovy teploperedachi. 2-e izd., stereotip. - M.: Energiya, 344 p. (in Russian)
8. Tsvetkov, F.F., Grigorev, B.A. 2005. Teplomassoobmen : ucheb. posobie. 2-e izd., ispr. i dop. - M.: Izdatelstvo MEI, -550 p. (in Russian) 9. Deev, V. I., Zar Ni Aung, Kutsenko, K. V., i dr. 2011. Yadernaya fizika i inzhiniring, 2 (5), 387-394. (in Russian)

10. Tolubinskiy, V. I. 1980. Teploobmen pri kipenii. - K.: Naukova dumka. - 316 p. (in Russian)

11. Vinogradov, S.N., Tarantsev, K.V., Vinogradov, O. S. 2001. Vyibor i raschet teploobmennikov: ucheb. posobie. - Penza: Penza state university, - 100 p. (in Russian)

12. Altunin, V.V. Geller V.Z., Kremenevskaya E.A. i dr. 1985. Teplofizicheskie svoystva freonov: $v 2$ t. T. 2 : Freony metanovogo ryada. Spravochnyie dannyie pod red. S. L. Rivkina. - M.: Izd. standartov, 264 p. (in Russian)

13. Perelshteyn, I.I., Parushin, E.B., 1984. Termodinamicheskie i teplofizicheskie svoystva rabochih veschestv holodilnyih mashin i teplovyih nasosov. - M.: Legkaya i pischevaya prom. - 232 p. (in Russian)

14. A Study of Evaporation Heat Transfer Coefficient Correlations at Low Heat and Mass Fluxes for Pure Refrigerants and Refrigerant Mixtures. ACRC University of Illinois; principal investigator J. C. Chato. - ACRC TR-32. - Urbana, 1993. - 21 p.

Отримана в редакції 09.09.2014, прийнята до друку 17.11.2014 